\title{
OS SIGNIFICADOS DOS NÚMEROS RACIONAIS: UM OLHAR A PARTIR DO LIVRO DIDÁTICO
}

\author{
THE MEANINGS OF RATIONAL NUMBERS: A LOOK FROM THE TEACHING BOOK \\ MARCIA VIARO FLORES* \\ VANILDE BISOGNIN**
}

\section{RESUMO}

0 presente trabalho tem como objetivo investigar quais significados dos números racionais são privilegiados em uma coleção de livros didáticos de Matemática do Ensino Fundamental. Para isso, optou-se por um estudo de natureza qualitativa associado a uma análise documental, a qual teve como foco os distintos significados dos números racionais. Para análise, foram considerados tantos os exemplos como as atividades propostas nos capítulos referentes a esse conteúdo. Como resultados, observou-se a predominância dos significados operador e parte-todo, em detrimento dos significados medida, quociente e razão. Ainda, nas atividades propostas, detectou-se um trabalho centrado nos procedimentos matemáticos com pouca exploração dos conceitos.

Palavras-chave: Números racionais. Livro didático. Significados.

\section{ABSTRACT}

The present work aims to investigate which meanings of rational numbers are privileged in a collection of elementary school mathematics text books. For this, we opted for a qualitative study associated with a documentary analysis that focused on the different meanings of rational numbers. For analysis, both the examples and the activities proposed in the chapters referring to this content were considered. As results we observed the predominance of the meanings operator and part-whole, in detriment of the meanings measure, quotient and reason and, in the proposed activities, the work is centered in the mathematical procedures with little exploration of the concepts.

Keywords: Rational numbers. Text book. Meanings.

\footnotetext{
* Doutoranda do Programa de Pós-Graduação em Ensino de Ciências e Matemática da Universidade Franciscana, Santa Maria, RS. E-mail: marciaviaroflores@gmail.com; https://orcid.org/0000-0002-0744-4091.

** Doutora em Matemática e Pesquisadora do Programa de Pós-Graduação em Ensino de Ciências e Matemática da Universidade Franciscana, Santa Maria, RS. E-mail: vanilde@ufn.edu.br; https://orcid.org/0000-0001-5718-4777.
} 


\section{INTRODUÇÃO}

Os números racionais estão presentes na trajetória escolar dos estudantes desde muito cedo. Como previsto na Base Nacional Comum Curricular (BNCC), esse conteúdo deve ser introduzido nos anos iniciais do Ensino Fundamental, sendo que a expectativa é que os estudantes resolvam problemas envolvendo números racionais com representação decimal finita e também desenvolvam habilidades de leitura, escrita e ordenação desses números (BRASIL, 2017).

No entanto, percebe-se a dificuldade que esse conteúdo gera, tanto no processo de ensino quanto na aprendizagem de seus conceitos. Campos e Rodrigues (2007), ao tratarem dos números racionais, destacam os obstáculos que surgem na compreensão dos conceitos relacionados a esse tema.

Dentre os conteúdos típicos da Matemática do ensino básico, os números racionais constituem-se em um dos temas de construção mais difícil, pois sua compreensão envolve uma variedade de aspectos que se configuram como obstáculos ao seu pleno domínio, pois, embora esse conjunto numérico seja uma extensão dos naturais, as tentativas de estabelecer paralelos entre procedimentos relativos aos dois conjuntos ora são válidas, ora não são, deixando desorientados os alunos que procuram estabelecer esses paralelos, sem uma reflexão mais aprofundada (CAMPOS; RODRIGUES, 2007, p. 69).

A abordagem dos distintos significados associados aos números racionais deve começar a ser trabalhada nos anos iniciais do Ensino Fundamental, tendo continuidade durante toda a vida escolar. Neste sentido, pode-se observar, na BNCC, o destaque, já no quinto ano, para o trabalho com os significados da representação fracionária dos números racionais (BRASIL, 2017).

Assim, enfatiza-se a importância da compreensão dos diferentes significados associados aos números racionais, os quais, muitas vezes, são desconhecidos pelos professores que ensinam esse conteúdo.

Marinho e Mandarino (2013) destacam o esforço que pesquisadores têm feito no intuito de produzirem trabalhos que se voltem ao ensino dos números racionais, dada a complexidade que esse assunto apresenta e também face ao baixo desempenho de estudantes em avaliações de larga escala.

Esses baixos índices de aproveitamento têm gerado a necessidade de repensar o modo como se está ensinando Matemática. De modo geral, reconhece-se que o uso de tecnologias, de jogos e de distintas metodologias tem sido incorporado em sala de aula. Todavia, o livro didático ainda desempenha um papel central na sala de aula, já que, por vezes, é o único recurso disponível aos alunos.

Souza e Wielewski (2012) destacam a contribuição do livro didático para os processos de ensino e aprendizagem, pois esse consegue dialogar tanto com o professor quanto com 0 aluno. Ademais, continua sendo uma das ferramentas metodológicas mais utilizadas na condução das aulas.

Nesse sentido, este estudo pretende investigar quais os significados de número racional estão presentes em uma coleção de livros didáticos de Matemática do Ensino Fundamental, baseando-se nos significados propostos por Kieren (1980).

Essa escrita organiza-se a partir dessa introdução, na qual é apresentado o tema; na sequência, são apresentados os distintos significados dos números racionais definidos por Kieren (1980); no item seguinte, descrevem-se os caminhos metodológicos adotados; posteriormente, apresentam-se os resultados e discussões e, por fim, são tecidas algumas conclusões sobre 0 assunto investigado. 


\section{OS SIGNIFICADOS DOS NÚMEROS RACIONAIS}

Os números racionais apresentam uma variedade de significados e, para que o estudante apresente uma plena compreensão de seu conceito, é importante que ele tenha consciência deles.

Em 1976, Kieren apresentou seu primeiro trabalho tratando dos diferentes significados que os números racionais possuem e, em 1980, refinou sua pesquisa, apresentando cinco ideias principais de números fracionários, as quais emergem como base para a construção de números racionais, a saber: parte-todo, quociente, medida, razão e operador.

Essas cinco ideias não são matematicamente independentes, mas representam cinco padrões de pensamento quando se trata de números racionais. Na sequência, são apresentadas cada uma delas.

\section{Parte-todo}

0 significado parte-todo, em geral, é o primeiro utilizado quando se inicia o estudo dos números racionais na representação fracionária, aparecendo nas primeiras discussões relacionadas a esse conceito nos livros didáticos. Também está diretamente relacionado aos outros significados que 0 número racional pode assumir.

Na concepção de Kieren (1980), o significado parte-todo emerge quando é dividido o todo em partes "iguais" e é considerado um número designado dessas partes, sendo que a divisão pode ser realizada tanto em uma grandeza contínua (comprimento, área, volume, etc.) quanto em uma grandeza discreta (coleção de objetos).

Ao se associar o símbolo $\frac{a}{b}$, é interessante observar que representa a quantidade de partes "iguais", em que 0 inteiro está dividido, e representa a quantidade de partes consideradas.

Silva (2005, p. 107) destaca que um dos tipos de tarefas mais frequentes, que mobiliza 0 significado parte-todo, é a que solicita "a quantificação ou a identificação de parte de um inteiro, em figuras que representem grandezas contínuas ou discretas."

Para a compreensão desse significado, é importante que 0 estudante desenvolva algumas habilidades importantes, como destaca Charalambous e Pitta-Pantazi (2007). Tais habilidades contemplam a capacidade de entender que as partes em que 0 todo foi dividido devem ter 0 mesmo tamanho; que se pode particionar tanto uma área contínua quanto um conjunto discreto; que existem relações entre as partes e 0 todo, como, por exemplo, que todas as partes juntas devem formar 0 todo; que, quanto mais partes são produzidas do todo, menor será a parte; que a relação entre as partes e o todo é sempre preservada, independente do tamanho, forma disposição ou orientação das partes produzidas e, ainda, que se pode construir o todo com base em suas partes.

\section{Razão}

Conforme Kieren (1980), a razão pode ser entendida como a comparação quantitativa entre duas qualidades e, nesse sentido, a ideia de partição não caberia para esse significado.

Silva (2005), ao descrever as ideias associadas à concepção de razão, destaca que essa nos encaminha, naturalmente, para o raciocínio proporcional, sendo que a representação $\frac{a}{b}$ pode ser entendida como um índice comparativo. 
A proporcionalidade envolve diretamente a equivalência de números fracionários e caracteriza-se como uma ferramenta poderosa para a resolução de problemas. $\mathrm{Na}$ descrição inicial da situação, uma constante é apresentada, implícita ou explicitamente, determinada por uma relação particular entre e , em que qualquer mudança em provoca uma mudança previsível em (SILVA, 2005, p. 125).

Nesse mesmo sentido, Charalambous e Pitta-Pantazi (2007) explicitam que a compreensão do significado razão presume que 0 estudante desenvolva a habilidade de reconhecer a proporcionalidade estabelecida entre as quantidades quando há modificações nestas.

\section{Quociente}

0 significado quociente pode ser visto como a quantificação do resultado da divisão de uma quantidade em um determinado número de partes (KIEREN, 1980). Nesse caso, o símbolo $\frac{a}{b}$ representa 0 resultado de uma distribuição de $a$ em $b$ partes.

Segundo Charalambous e Pitta-Pantazi (2007), a compreensão do significado quociente pressupõe o desenvolvimento de algumas habilidades, dentre elas:

a) identificar a fração com divisão, compreendendo o papel do dividendo e do divisor;

b) entender as diferenças em contextos discretos e contínuos;

c) compreender que a divisão pode ser vista em dois sentidos: partitiva e quotativa. A divisão partitiva enfatiza a quantidade que cada participante receberá se a quantidade for equipartida. Por exemplo, se tomarmos 3 pizzas para dividir em 4 pessoas, o estudante deve compreender que cada pizza deve ser dividida em 4 partes, e cada indivíduo toma 3 dessas partes. Por outro lado, a divisão quotativa dá ênfase ao número de divisões iguais, por exemplo, três pizzas são compartilhadas entre alguns amigos, sendo que cada amigo recebe $\frac{3}{4}$. Nesse caso, a questão que pode ser posta é quantos amigos há.

\section{Medida}

A atividade de medir significa atribuir um número a uma região, podendo essa ser unidimensional, bidimensional, tridimensional, dentre outras. Isso, geralmente, é feito por meio de uma "iteração do processo de contagem do número de unidades inteiras utilizáveis na 'cobertura' da região, subdividindo igualmente uma unidade para fornecer o recurso adequado. 0 foco aqui é na unidade arbitrária e sua subdivisão, e não nas relações parte-todo" (KIEREN, 1980, p. 136).

Com as tarefas envolvendo medições, é possível perceber as limitações que o conjunto dos números naturais apresenta e, assim, entender a necessidade de "novos números" para a quantificação adequada de comprimentos (SILVA, 2005).

Em geral, ao trabalhar com a medida de comprimento, utiliza-se uma reta numérica e 0 entendimento que $\frac{1}{b}$ representa a subunidade considerada, ou seja, a unidade é dividida em partes e então será $\frac{a}{b}$ o resultado da medição realizada. Nesse sentido, "0 número fracionário $\frac{a}{b}$ obtido permitirá a compreensão de que a subunidade $\frac{1}{b}$ foi utilizada vezes na medição efetuada" (SILVA, 2005, p. 118).

De acordo com Charalambous e Pitta-Pantazi (2007), é possível também associar a ideia de medida à distância a um determinado ponto inicial. A título de exemplo, $\frac{3}{4}$ pode ser visto como a 
distância 3 de $\frac{1}{4}$ de um dado ponto. Os autores chamam a atenção para o fato de que 0 significado medida é, geralmente, associado a retas numéricas ou a instrumentos de medição, como réguas.

Para o significado medida, o estudante também deve desenvolver habilidades para ter uma boa compreensão. Para ilustrar isso, ele deve ser capaz de fazer partições da unidade; ter noção de ordem e compreender a noção de equivalência.

\section{Operador}

0 significado operador retrata os números racionais como mecanismos que mapeiam um conjunto multiplicativamente em outro conjunto. Ao se considerar o operador $\frac{a}{b}$, pode-se observar duas operações: dividir por $b$ e multiplicar por $a$, podendo ser interpretado como uma função que transforma um conjunto em outro conjunto (KIEREN, 1980).

Ao se trabalhar com conjuntos contínuos, consegue-se interpretar o operador como processos de esticar e de encolher; já com conjuntos discretos, é possível se pensar em combinações de multiplicadores e de divisores.

Podemos afirmar então que o operador é uma máquina que reduz ou amplia a quantidade ou o número em quantidades contínuas e também que opera como multiplicador ou divisor em quantidades discretas. Sendo assim, a fração atua como um valor escalar aplicado a uma determinada quantidade (LAPA, 2013, p. 41).

Nesse sentido, Charalambous e Pitta-Pantazi (2007), igualmente, destacam algumas habilidades que os estudantes devem adquirir para trabalhar com o significado operador, como a capacidade de interpretar o operador de várias formas associadas às interpretações de encolher/esticar ou ampliar/ reduzir; de entender 0 operador como uma multiplicação e entender que esse pressupõe um resultado.

\section{METODOLOGIA}

Este estudo caracteriza-se como qualitativo, já que procura trabalhar com o universo de significados que corresponde a um espaço mais profundo de relações, processos e fenômenos (MINAYO, 1994), associado a uma análise documental, pois vale-se de material que ainda não recebeu um tratamento analítico ou que pode ser reelaborado de acordo com os objetivos da pesquisa (GIL, 2002).

Para tanto, selecionou-se a coleção de livros didáticos de Matemática do Ensino Fundamental, intitulada Matemática - Coleção Convergências, de autoria de Chavante (2015). Essa coleção faz parte do Programa Nacional do Livro Didático (PNLD) do ciclo 2017 - 2018 - 2019 e foi escolhida por estar sendo utilizada nas escolas do município de uma das pesquisadoras.

A coleção analisada apresenta quatro livros, correspondentes aos anos finais do Ensino Fundamental. 0 Quadro 01 apresenta informações relevantes sobre os manuais estudados. 
Quadro 1 - Categorização dos capítulos da coleção analisada

\begin{tabular}{|c|c|c|}
\hline Ano & Número total de capítulos & Capítulos que abordam números racionais \\
\hline $6^{0}$ & 13 & 3 \\
\hline $7^{0}$ & 10 & 1 \\
\hline $8^{0}$ & 10 & 1 \\
\hline $9^{0}$ & 10 & - \\
\hline
\end{tabular}

Fonte: Autoria própria

No livro do sexto ano, não foi encontrado o termo "número racional", porém notou-se que as ideias relacionadas às frações e aos números decimais fazem parte do assunto investigado. 0 autor apresenta, nesse manual, três capítulos, sendo um deles intitulado Frações; na sequência, há um capítulo intitulado Números Decimais e, por último, é apresentado um capítulo que trata das operações com números decimais.

No caso desse trabalho, optou-se por analisar no livro do sexto ano em específico, o capítulo que apresenta os conceitos iniciais de números racionais na forma fracionária.

No livro do sétimo ano, o autor apresenta um capítulo intitulado "Números Racionais", o qual trata das formas fracionária e decimal, da representação do número racional na reta numérica e das operações com números racionais.

No livro do oitavo ano, identificou-se o assunto estudado em um capítulo denominado "Conjuntos Numéricos". Nesse, é feita menção aos conjuntos dos números naturais, inteiros, racionais, irracionais e reais.

Para identificar os diferentes significados dos números racionais, criou-se uma matriz de categorização que levou em conta os cinco significados propostos por Kieren (1980), observando as atividades propostas pelo autor da coleção analisada. Posteriormente, os dados foram compilados (Ver Quadro 02) a fim de responder à questão de pesquisa.

Quadro 2 - Matriz de categorização de exemplos e exercícios

\begin{tabular}{|c|c|c|c|c|c|c|c|c|}
\hline \multirow{2}{*}{$\begin{array}{c}\text { Significados associados aos } \\
\text { números racionais }\end{array}$} & \multicolumn{4}{|c|}{ Exemplos } & \multicolumn{4}{c|}{ Exercícios } \\
\cline { 2 - 10 } & $\mathbf{6}^{\mathbf{0}}$ & $\mathbf{7}^{\mathbf{0}}$ & $\mathbf{8}^{\mathbf{0}}$ & $\mathbf{9}^{\circ}$ & $\mathbf{6}^{\mathbf{0}}$ & $\mathbf{7}^{0}$ & $\mathbf{8}^{\mathbf{0}}$ & $\mathbf{9}^{\circ}$ \\
\hline Parte-todo & 11 & 1 & - & - & 7 & 2 & 1 & - \\
\hline Quociente & 1 & - & - & - & 4 & 2 & 1 & - \\
\hline Medida & - & 2 & 1 & - & - & 1 & 1 & - \\
\hline Razão & - & - & - & - & - & - & - & - \\
\hline Operador & - & - & - & - & 16 & - & - & - \\
\hline
\end{tabular}

Fonte: Autoria própria

Na próxima seção, são apresentados e discutidos alguns dos exemplos e exercícios os quais foram classificados na matriz. 


\section{RESULTADOS E DISCUSSÕES}

Este item do texto está organizado de acordo com os resultados obtidos da análise do livro de cada ano, a fim de facilitar a compreensão.

A expressão "número racional" só aparece, na coleção analisada, no livro correspondente ao sétimo ano, como já mencionado. Ainda assim, entende-se que as ideias relacionadas às frações que são apresentadas no livro do sexto ano formam a base para 0 estudo do conjunto dos números racionais. Logo, o capítulo destinado ao estudo das frações do livro do sexto ano foi incluído na análise realizada. Além desse, foram analisados o capítulo denominado "Números Racionais" do livro do sétimo ano e também o capítulo do livro do oitavo ano, que trata de conjuntos numéricos.

\section{Livro $6^{\circ}$ ano}

No capítulo intitulado Frações, do livro do sexto ano, o autor começa com alguns exemplos para falar das ideias iniciais que envolvem frações, apresentando objetos de uso cotidiano, como jarra graduada, brocas e marcadores de combustível, os quais apresentam marcações envolvendo frações. Além disso, apresenta uma pequena introdução histórica sobre o uso de frações no Egito Antigo e introduz a nomenclatura de numerador e de denominador.

A seguir, o autor observa que "Dependendo da situação, as frações são utilizadas com ideias diferentes" (CHAVANTE, 2015a, p. 156), destacando três dessas ideias. Nesse momento, percebe-se que 0 autor começa a tratar dos diferentes significados ao introduzir o conteúdo e, na sequência, são discutidos os exemplos relacionados a esses diferentes significados que a coleção apresenta.

0 primeiro significado citado é a fração vista como parte de um inteiro. Na Figura 1, apresenta-se 0 desenvolvimento que 0 autor faz, em torno dessa ideia, com um exemplo.

Figura 1 - Exemplo do significado parte-todo

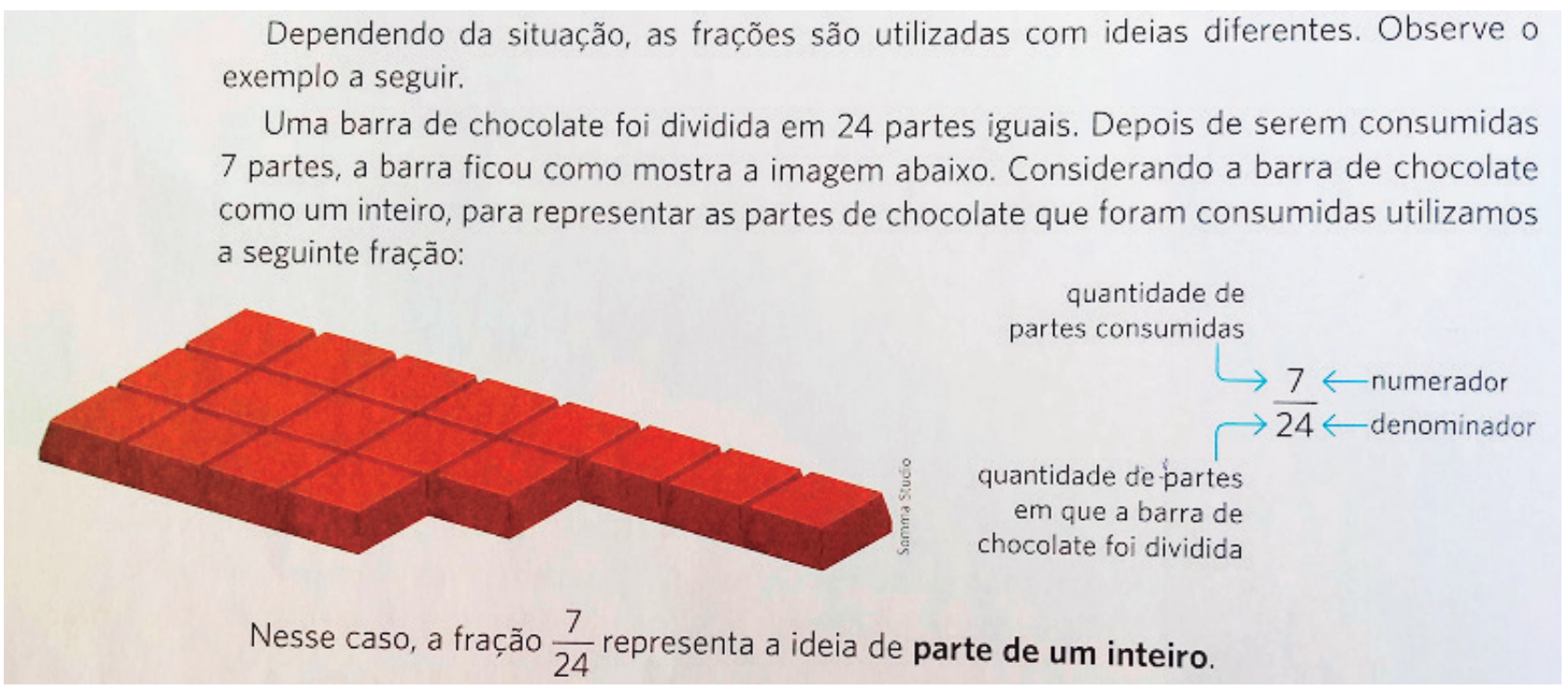

Fonte: Chavante, 2015a, p. 156 
0 segundo significado vinculado à fração, o qual é discutido pelo autor, é 0 de quociente de uma divisão, como pode ser visto na Figura 2.

Figura 2 - Exemplo do significado quociente

Também podemos relacionar a fraçăo com o quociente de uma divisão. A fração $\frac{4}{4^{\prime}}$ por exemplo, correspondente à quantidade de leite no recipiente ao lado, que representa 1 inteiro, pois $\frac{4}{4}=1$. Como $4: 4=1$, temos que $\frac{4}{4}=4: 4=1$. Assim, o traço da fração representa uma divisão.

Toda fração pode ser escrita em forma de divisão. O denominador de uma fração não pode ser zero, pois não existe divisão por zero.

Fonte: Chavante, 2015a, p. 157

A razão é ressaltada como uma terceira ideia associada às frações. Nesse caso, destaca-se que esse significado, atribuído pelo autor, difere do trazido por Kieren (1980), já que, no exemplo, não se tem comparação entre duas qualidades. No caso, o exemplo aproxima-se mais do significado parte-todo.

Figura 3 - Exemplo do significado razão

A fração também pode ser utilizada como uma razão. No armário representado abaixo, por exemplo, há 10 camisetas, das quais 3 são brancas. Podemos representar a quantidade de camisetas brancas desse armário pela fraçăo $\frac{3}{10}$, ou seja, 3 das 10 camisetas são brancas, ou, ainda, a quantidade de camisetas brancas está na razäo de 3 para 10.

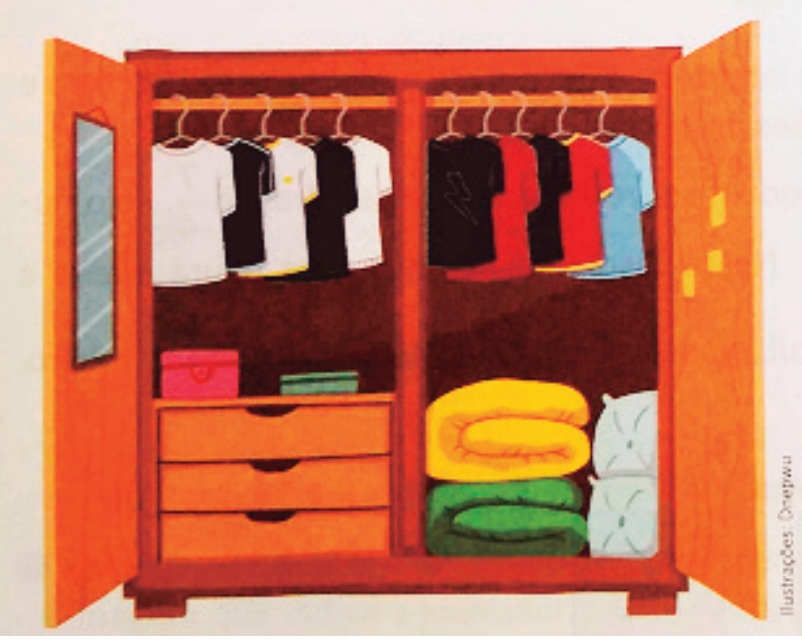

As fraçöes que possuem denominadores iguais a 10, 100, $1000, \ldots$ säo chamadas de fraçöes decimais.

Escreva uma fração para representar a quantidade de camisetas azuis nesse armário.

Fonte: Chavante, 2015a, p. 157 
0 significado operador não foi abordado explicitamente nos exemplos de introdução ao conteúdo. Entretanto, em uma das atividades propostas no livro do sexto ano, o autor faz a resolução de uma situação proposta, explicando o significado da fração como operador.

Quanto às atividades que a coleção apresenta, no livro do sexto ano, contabilizou-se um total de 54, as quais foram categorizadas de acordo com os cinco significados: parte-todo, operador, quociente, razão e medida. Ainda, algumas atividades não foram enquadradas em nenhuma dessas categorias, por se tratarem, por exemplo, de classificar frações como aparentes ou não, simplificar frações ou de atividades em que era solicitado que se encontrassem resultados de operações com frações.

Na Figura 4, apresenta-se a atividade destacada anteriormente acerca do significado operador. Nesse caso, 0 autor faz uma explicação do procedimento para encontrar o resultado pedido de uma primeira indagação e, após, propõe ao estudante duas questões para que esse responda.

Figura 4 - Exercício sobre 0 significado operador.

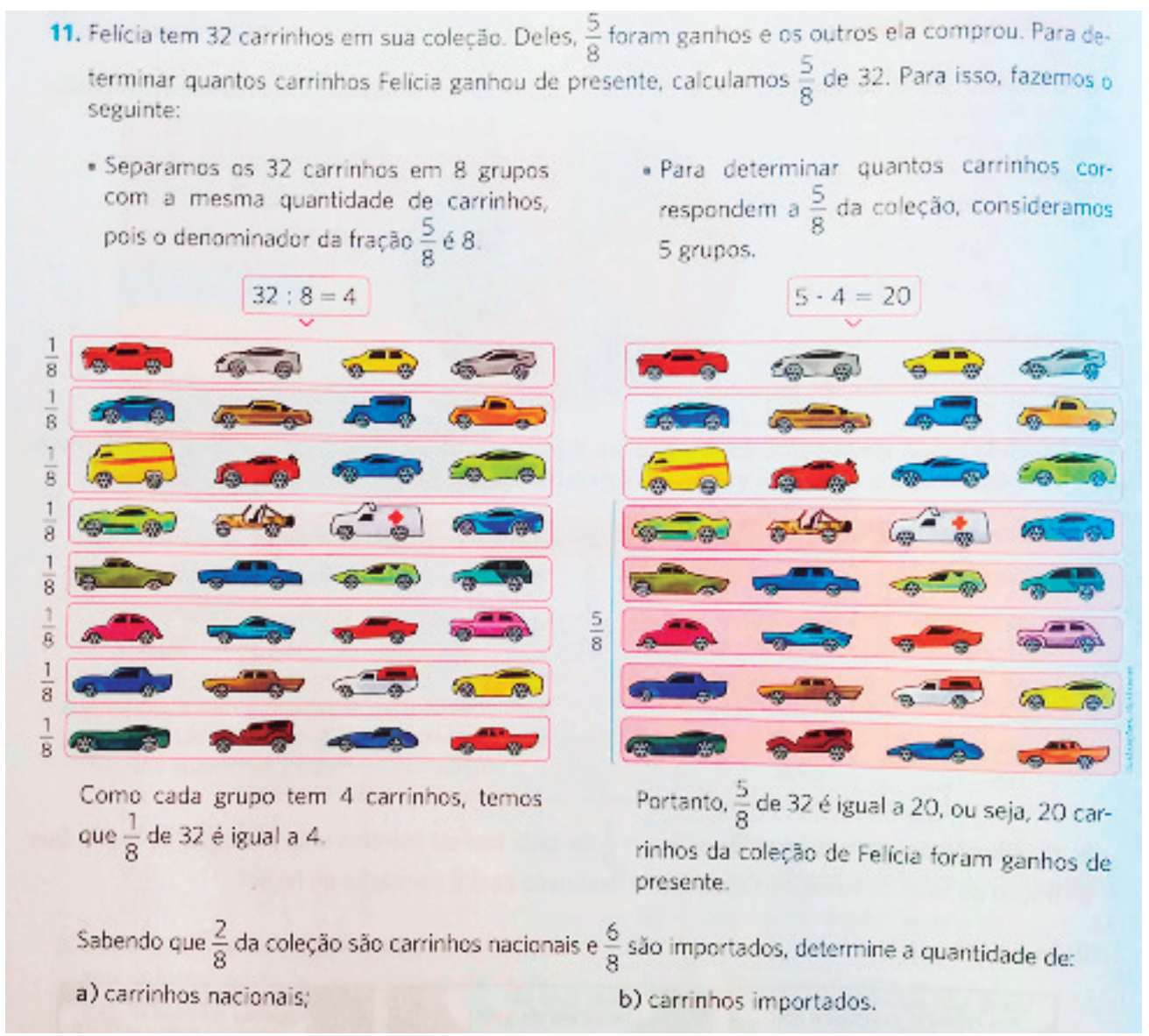

Fonte: Chavante, 2015a, p. 164 
Percebe-se, a partir desse exercício, que a proposta de atividade feita pelo autor diz respeito ao significado operador descrito por Kieren (1980) e apresentado anteriormente.

No livro do sexto ano, de todas as atividades analisadas, o significado operador foi 0 mais encontrado, segundo a categorização proposta. Já o significado parte-todo foi 0 segundo mais encontrado na categorização. Na Figura 5, é apresentado o exemplo de uma atividade que mobiliza esse significado.

Figura 5 - Exercício sobre 0 significado parte-todo

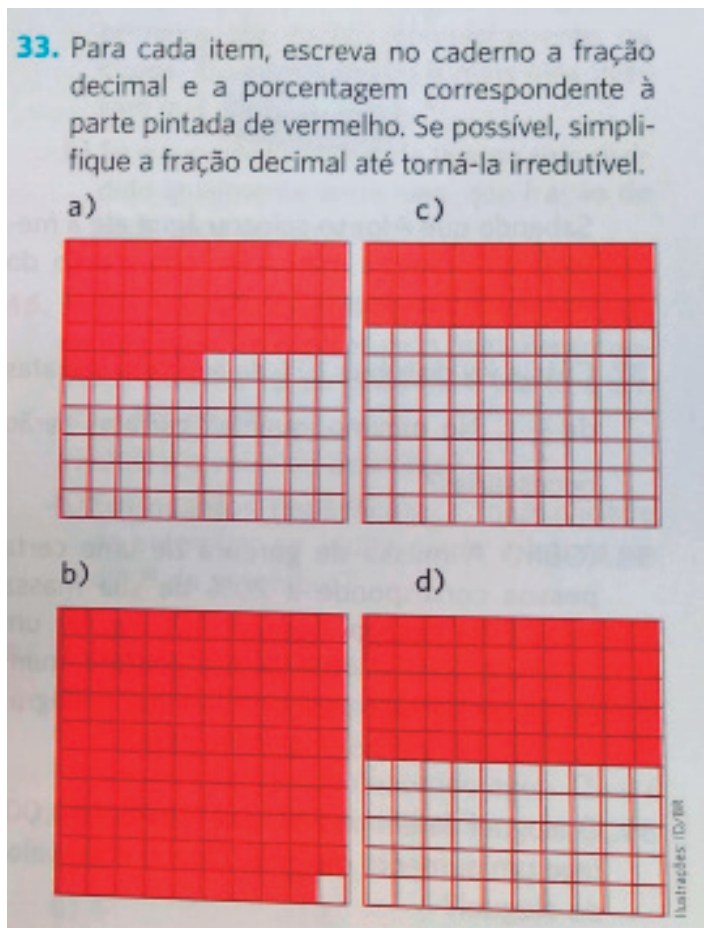

Fonte: Chavante, 2015a, p. 177

Nesse caso, 0 autor propõe uma atividade que mobiliza além da contagem das partes em relação ao todo para responder ao pedido. Trata-se de um exercício que prevê que o estudante faça a conversão da fração decimal em porcentagem.

0 significado quociente não teve tanto destaque em termos de quantidade de atividades propostas na categorização realizada, mas responde pelo terceiro significado mais abordado. Pode-se observar um exemplo de atividade que envolve esse significado na figura abaixo. 
Figura 6 - Exercício sobre o significado quociente

10. Leia a tira.
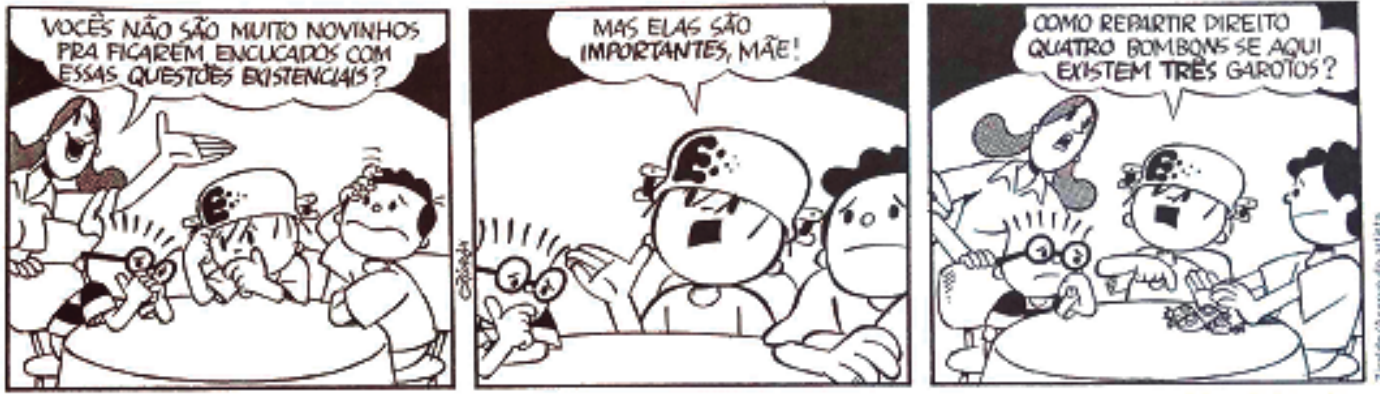

ZIRALDO. O menino moukquinhoc as melhores tiras, 1. Porto Alegre: L\&PM, 1995. p. 36.

a) Em sua opiniăo, por que os meninos estăo aflitos?

b) Escreva a fraçăo que representa a quantidade de bombons que cada um iria receber.

c) A fração que você indicou no item b representa mais que um inteiro. Como são chamadas as fraç̋̄es que têm essa característica?

d) Como você faria para repartir quatro bombons para três pessoas?

Fonte: Chavante, 2015a, p. 163

Os significados razão e medida não foram encontrados nas atividades analisadas do livro do $6^{0}$ ano.

\section{Livro $7^{0}$ ano}

Conforme já destacado anteriormente, no livro do sétimo ano, encontra-se a definição de número racional, que é dada como "Todo número que pode ser escrito como quociente de dois números, com o divisor diferente de zero" (CHAVANTE, 2015b, p. 44). Na sequência, o autor discute a localização de um número racional na reta numérica.

Nesse caso, entende-se que 0 autor buscou trabalhar com o significado medida, mesmo sem tê-lo mencionado. Na Figura 7, tem-se um trecho da explicação de como localizar um número racional na forma fracionária na reta numérica.

Figura 7 - Exemplo do significado medida

O número $\frac{1}{4}$ está localizado entre os números 0 e 1. Dividimos este intervalo em quatro partes iguais e indicamos o ponto correspondente à primeira parte no sentido positivo.

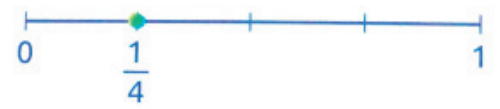

Fonte: Chavante, 2015b, p. 45 
Quanto às atividades, no livro correspondente ao sétimo ano, Chavante apresenta as formas fracionária e decimal em um mesmo capítulo sobre números racionais, totalizando 65 atividades. Nesse caso, analisaram-se as atividades que apresentam a forma fracionária do número racional. A maioria das questões são vinculadas a procedimentos operacionais ou de ordenação, sendo que apenas 5 atividades puderam ser vinculadas a algum significado, sendo 2 relacionadas ao significado parte-todo, 2 ao significado quociente e 1 relacionada ao significado medida.

Os significados razão e operador não foram encontrados na classificação proposta.

\section{Livro $8^{\circ}$ ano}

Quanto ao livro do oitavo ano, o estudo do conjunto numérico dos números racionais é restrito a poucas páginas. Esse tipo de estudo somente é mencionado em uma seção que aborda os conjuntos dos números naturais, inteiros e racionais. 0 autor destaca que, em situações de divisão, o conjunto dos números inteiros pode não ser suficiente, sendo necessário o conjunto dos números racionais para lidar com quantidade não inteiras. Após, apresenta a definição de um número racional e algumas ideias ligadas ao fato de que, entre dois números inteiros, existem infinitos números racionais.

Nesse livro, encontram-se apenas 13 atividades vinculadas a esse conteúdo. Novamente, 0 autor aborda as representações fracionária e decimal dos números racionais, e o foco foi nas questões que trouxeram a representação fracionária com algum significado observado. A grande maioria das questões se relaciona à forma decimal e, em função disso, tem-se apenas três atividades destacadas no Quadro 2, vinculadas aos significados parte-todo, quociente e medida.

\section{Algumas Considerações}

Após serem concluídas as análises dos livros da coleção escolhida, notou-se a predominância dos significados parte-todo e operador. Esses abrangeram a maioria das questões que foram categorizadas. Essa predominância de significados, em detrimento de outros, aparece como resultado de outras pesquisas, com foco próximo ao trabalho aqui apresentado, como se percebe nos trabalhos de Carvalho (2017), Lapa (2013) e Lessa (2011).

Na pesquisa de Carvalho (2017), foram analisados seis livros correspondentes ao sexto ano do Ensino Fundamental a fim de verificar a abordagem dada às frações nesses materiais. Nessas obras, 0 autor detectou que 0 significado parte-todo foi o mais utilizado nas abordagens, seguido do significado de operador multiplicativo. Os outros significados, segundo 0 autor, são trabalhados de maneira mais branda. 0 autor destaca também que para dar início ao estudo das frações, os livros didáticos não levam em consideração todos os diferentes significados, o que pode acarretar uma formação deficitária nos estudantes que utilizam esses livros.

Lapa (2013), ao fazer a análise um livro didático do sétimo ano, concluiu que o significado mais enfatizado foi o de operador multiplicativo, seguido pelos significados número, parte-todo e medida. 0 significado quociente não foi observado no livro didático analisado.

Na pesquisa de Lessa (2011), a autora analisou livros didáticos referentes à série na qual as frações são abordadas com mais ênfase, escolhendo para sua análise livros que datam desde 1927 até 2010. Nos seus achados, destaca que os significados mais abordados são parte-todo e operador e que 0 livro mais antigo analisado é o que trabalha com a maior variedade de significados para os números racionais. 
Lessa (2011) destaca dois pontos problemáticos, que ocorrem em muitas salas de aula: a abordagem dos números racionais baseada em apenas um significado, e a predominância de questões que dão ênfase muito mais a procedimentos do que a conceitos, gerando problemas de compreensão aos estudantes. "Outra questão se refere à abordagem conceitual realizada na sala de aula, o ensino baseado apenas no significado "parte-todo", com uma abordagem rápida, seguida de um trabalho excessivo com as operações, prevalecendo o caráter algébrico ao conceitual” (LESSA, 2011, p.48).

Apesar de, na afirmação, ser o significado parte-todo que prevaleça, as questões apresentadas de trabalho excessivo com operações e a predominância de atividades envolvendo procedimentos, também foram observadas na coleção de livros analisada em nossa pesquisa.

No caso da medida, no trabalho relatado nesse artigo, são poucas as atividades encontradas que abordam esse significado. Quando encontradas, essas se concentram na marcação de pontos na reta numérica. Já para 0 significado quociente, também foram restritas as questões apresentadas. "Assim, os significados menos abordados, "quociente" e "medida", provém de questões cotidianas da sociedade, como a necessidade de medições e a divisão, como já foi discutido. No entanto, estas são desconsideradas ou pouco valorizadas pelos livros didáticos" (LESSA, 2011, p. 52).

Para o significado razão, no sentido de Kieren, não foi possível identificar nenhuma atividade que tratasse desse significado. Talvez um dos motivos de não se ter encontrado esse significado é 0 exposto por Lessa (2011) quando afirma que a razão não é muito trabalhada no sexto ano, uma vez que a abordagem, geralmente, é feita quando são estudadas as proporções.

Ao se observar que o livro didático é uma importante ferramenta de auxílio ao professor, nos processos de ensino, entende-se que esse trabalho pode colaborar no sentido de alertar o docente para que adote uma postura crítica em relação ao livro didático utilizado. Nesse sentido, concorda-se com Carvalho (2017) quando esse afirma que os livros didáticos "Exploram em demasia alguns significados em detrimento de outros, podendo deixar o estudante sem a compreensão de algumas dessas situações. 0 que, sem a devida intervenção do professor, poderá acarretar uma formação deficitária no que diz respeito ao conceito de frações" (CARVALHO, 2017, p. 42).

Outro ponto que se considera importante de ser ressaltado é que os números racionais ocupam um espaço restrito na coleção de livros analisados, tendo em vista a complexidade de ideias envolvidas nos processos de ensino e de aprendizagem desse conteúdo. Percebe-se que a apresentação mais aprofundada ocorre no livro do sexto ano, quando 0 autor apresenta as ideias iniciais sobre frações; nos livros do sétimo e oitavo anos, os conceitos são apresentados de forma breve e sem muito aprofundamento nos diferentes significados e, no livro do nono ano, esse conteúdo nem aparece, apenas é mencionado como ferramenta para resolução de questões envolvendo outros conteúdos.

\section{CONCLUSÕES}

Este estudo procurou investigar quais significados dos números racionais podem ser observados em uma coleção de livros didáticos de matemática para o ensino fundamental. Por meio das análises, detectou-se que 0 autor desenvolveu o conteúdo dando ênfase a alguns significados, como operador e parte-todo em detrimento de outros, que não foram abordados com o mesmo destaque.

Mesmo entendendo que o livro didático não se constitui na única ferramenta que 0 professor utiliza em sala de aula, nos processos de ensino, tem-se a consciência de que esse é um recurso importante. 
Portanto, quando da escolha do livro didático, o professor, ao analisá-lo, precisa estar atento às características do livro. No caso do ensino de números racionais, esse tipo de manual pode precisar oferecer maior variedade de determinadas situações de aprendizagem aos alunos, cabendo, a cada professor, fazer complementações para atender aos seus diferentes significados.

\section{AGRADECIMENTOS}

0 presente trabalho foi realizado com apoio da Coordenação de Aperfeiçoamento de Pessoal de Nível Superior - Brasil (CAPES) - Código de Financiamento 001.

\section{REFERÊNCIAS}

BRASIL. Ministério da Educação e da Cultura. Base Nacional Comum Curricular. Educação Infantil e Ensino Fundamental. 2017. Disponível em: https://bit.ly/20QegeH. Acesso em: 26 set. 2019.

CAMPOS, T. M. M.; RODRIGUES, W. R. A idéia de unidade na construção do conceito de número racional. Revista Eletrônica de Educação Matemática, Florianópolis, v. 2, n. 4, p. 68-93. 2007.

CARVALHO, E. S. Sequência didática: uma proposta para o ensino do conceito de fração. Dissertação (Mestrado Profissional em Matemática) - Universidade Federal do Tocantins. Arraias. 2017.

CHARALAMBOUS, C. Y.; PITTA-PANTAZI, D. Drawing on a theoretical model to study student' understanding of fractions. Educational Studies in Mathematics. v. 64, n. 3, p. 293-316, University of Michigan, School of Education: Springer Netherlands, 2007.

CHAVANTE, E. R. Convergências: matemática, $6^{0}$ ano: anos finais: ensino fundamental. 1. ed. São Paulo: Edições SM, 2015.

CHAVANTE, E. R. Convergências: matemática, $7^{0}$ ano: anos finais: ensino fundamental. 1. ed. São Paulo: Edições SM, 2015.

CHAVANTE, E. R. Convergências: matemática, $8^{\circ}$ ano: anos finais: ensino fundamental. 1. ed. São Paulo: Edições SM, 2015.

CHAVANTE, E. R. Convergências: matemática, $9^{\circ}$ ano: anos finais: ensino fundamental. 1. ed. São Paulo: Edições SM, 2015.

GIL, A. C. Como elaborar projetos de pesquisa. 4. ed. São Paulo: Atlas, 2002.

KIEREN, T. E. On the mathematical, cognitive and instructional foundation so frational number. In: LESH, R. (Ed.) Number and measurement: papers from a research workshop. Columbus, Ohio: Eric/Smeac, 1976, p. 101-144.

KIEREN, T. E. The rational number construct - its elements and mechanisms. In: KIEREN, T. (Ed.) Recent research on number learning. Columbus: Eric/Smeac, 1980, p. 125-150.

LAPA, C. M. S. 0 ensino de frações e seus diferentes significados: um estudo a partir do livro didático A Conquista da Matemática e dos registros dos cadernos de alunos do $7^{\circ}$ ano da rede municipal de Aracaju/SE. Dissertação (Mestrado em Ensino de Ciências Naturais e Matemática) - Universidade Federal de Sergipe. São Cristóvão. 2013. 
LESSA, V. E. A compreensão do conceito de número fracionário: uma sequência didática para o significado medida. Dissertação (Mestrado Profissionalizante em Ensino de Matemática) - Universidade Federal do Rio Grande do Sul. Porto Alegre. 2011.

MARINHO, A.; MANDARINO, M. C. F. As frações nos livros didáticos do sexto ano do ensino fundamental. Educação Matemática em Revista. v. 1, n. 14, p. 52-64, 2013.

MINAYO, M. C. de L. (Org.) Pesquisa social: teoria, método e criatividade. 21. ed. Petrópolis: Vozes, 2002.

SILVA, M. J. F. da.Investigando saberes de professores do ensino fundamental com enfoque em números fracionários para a quinta série. Tese (Doutorado em Educação Matemática) - Pontifícia Universidade Católica. São Paulo. 2005.

SOUZA, G. R. C.; WIELEWSKI, G. D. Números racionais: um diálogo entre os documentos oficiais e os livros didáticos. In: SEMINÁRIO SUL-MATOGROSSENSE DE PESQUISA EM EDUCAÇÃO MATEMÁTICA, 6, 2012, Campo Grande. Anais... Campo Grande, 2012.

RECEBIDO EM: 02 abr. 2019. CONCLUÍDO EM: 13 dez. 2019. 
